FULL RESEARCH ARTICLE

\title{
Predation impedes recovery of Sierra Nevada bighorn sheep
}

DANIEL J. GAMMONS ${ }^{1 *}$, JEFFERY L. DAVIS ${ }^{2}$, DAVID. W. GERMAN $^{1}$, KRISTIN DENRYTER ${ }^{3}$, JOHN D. WEHAUSEN ${ }^{4}$ AND THOMAS R. STEPHENSON ${ }^{1}$

${ }^{1}$ Sierra Nevada Bighorn Sheep Recovery Program, California Department of Fish and Wildlife, 787 North Main St., Suite 220, Bishop, CA 93514, USA

${ }^{2}$ USDA APHIS Wildlife Services, 3419A Arden Way, Sacramento, CA 95825, USA

${ }^{3}$ California Department of Fish and Wildlife, Wildlife Branch, 1010 Riverside Parkway, West Sacramento, CA 95605, USA

${ }^{4}$ White Mountain Research Center, 3000 East Line St., University of California, Bishop, CA 93514, USA

*Corresponding Author: daniel.gammons@wildlife.ca.gov

Translocation of animals into formerly occupied habitat is a key element of the recovery plan for Sierra Nevada bighorn sheep (Ovis canadensis sierrae), which are state (California) and federally listed as endangered. However, implementing Sierra bighorn translocations is a significant conservation challenge because of the small size of the extant population and the limited number of herds available to donate translocation stock. One such herd, the Mt. Langley herd, recently became unusable as a translocation source following a substantial population decline. At the time of listing in 1999, predation by mountain lions (Puma concolor; hereafter lion) was considered a primary threat to Sierra bighorn, and since then lion predation may have continued to limit the ability of source herds to provide translocation stock. We evaluated the relationship between lion predation and ewe survival rates within three source herds of the Southern Recovery Unit, compared lion abundance and ewe survival among years of varying predation levels, provided a range of estimated times for the Mt. Langley herd to recover to its former status as a translocation source, and determined if the rates lions have been removed to mitigate Sierra bighorn predation exceeded sustainable harvest guidelines. We found compelling evidence that lion predation has impeded the recovery of Sierra bighorn by reducing survival rates of adult ewes (and consequently, population growth) and by preying upon individuals that could have otherwise been translocated. Ewe survival was poor during years of extreme predation but even during years of typical predation, survival rates were below a level needed to ensure population growth, indicating that years with 
little or no lion predation may be necessary for the population to grow and meet recovery goals. Because the intensity of predation was related to lion abundance, monitoring lion populations could provide managers with advance warning of periods of extreme predation. We found that following a period of particularly extreme predation, the Mt. Langley herd decreased in abundance far below the threshold needed to be considered a source of translocation stock, resulting in the loss of approximately $25 \%$ of the recovery program's capacity for translocations. It is unclear how many years it will take for this herd to recover, but management actions to reduce lion predation are likely needed for this herd to grow to a size that can afford to donate individuals to translocation efforts in the near future, even when optimistic growth rates are assumed. We found that lion removal may also be needed to prevent predation from leading to Sierra bighorn population decline. Lion removal rates that have been implemented thus far are well below what would be needed to reduce the abundance the eastern Sierra lion population itself. We recommend continued monitoring of Sierra bighorn and sympatric lions and note that lion removal may be required to facilitate bighorn recovery for the foreseeable future.

Key words: additive mortality, endangered species, mountain lion, Ovis canadensis sierrae, predation, Puma concolor, removal, survival, translocation

Sierra Nevada bighorn sheep (Ovis canadensis sierrae; hereafter Sierra bighorn) are a distinct subspecies of bighorn sheep (Wehausen and Ramey 2000; Wehausen et al. 2005; Buchalski et al. 2016) that once ranged throughout much of California's Sierra Nevada, from Olancha Peak in the south to Sonora Pass in the north (Wehausen and Jones 2014). They disappeared from most of their native range following the appearance of Europeans, primarily from diseases of introduced domestic livestock, and continued to decline through most of the $20^{\text {th }}$ century (Wehausen et al 1987; Wehausen et al. 2011). By the early 1970s, when Sierra bighorn were included in the first list of species compiled under the California Endangered Species Act (Leach et al. 1974), they persisted in only three subpopulations (i.e., herds) near the community of Independence in the southern Owens Valley: Sawmill Canyon, Mt. Baxter, and Mt. Williamson (Wehausen and Jones 2014). Restoration actions during 1978-1979 re-established four additional herds in historic habitat and increased the total population from 250 (Wehausen 1980) to about 300 by 1985 (USFWS 2007). That success was followed by a severe decline in abundance to just over 100 animals by 1995 (USFWS 2007) coincident with a steep increase in mountain lion (Puma concolor, hereafter, lion) activity and documented predation upon Sierra bighorn (Wehausen 1996; USFWS 2007). It became clear that Sierra bighorn were on a trajectory towards extinction, and they were listed as endangered by the California Fish and Game Commission and the U.S. Fish and Wildlife Service (USFWS) in 1999 (USFWS 1999). Lion predation was considered a primary threat to Sierra bighorn at the time of listing (USFWS 1999, 2007). The California Department of Fish and Wildlife (hereafter, the Department) has led recovery efforts for Sierra bighorn since that time, guided by the Recovery Plan for Sierra Nevada Bighorn Sheep (USFWS 2007). 
The ultimate goal of recovery programs for endangered species is to 'delist' species after recovery goals are met. Recovery goals for Sierra bighorn specify abundance and distribution targets. Translocation has been the primary management tool to restore bighorn sheep to unoccupied habitat (Douglas and Leslie 1999) because of their slow rate of natural colonization (Geist 1971). Both an early conservation plan (Sierra Nevada Bighorn Sheep Interagency Advisory Group 1984) and the Recovery Plan for Sierra Nevada Bighorn Sheep (USFWS 2007) recognized the need to develop additional large herds capable of serving as sources of translocation stock, beyond the native geographically overlapping Sawmill Canyon and Mt. Baxter herds that had been used as the source populations for early translocations in the 1970s and 1980s (Fig. 1). That need was met in 2004 when Wheeler Ridge (initiated in 1979) became the first reintroduced herd used as a source for translocation. Translocation stock from the Mt. Langley (initiated in 1980) were used for the first time in 2008.

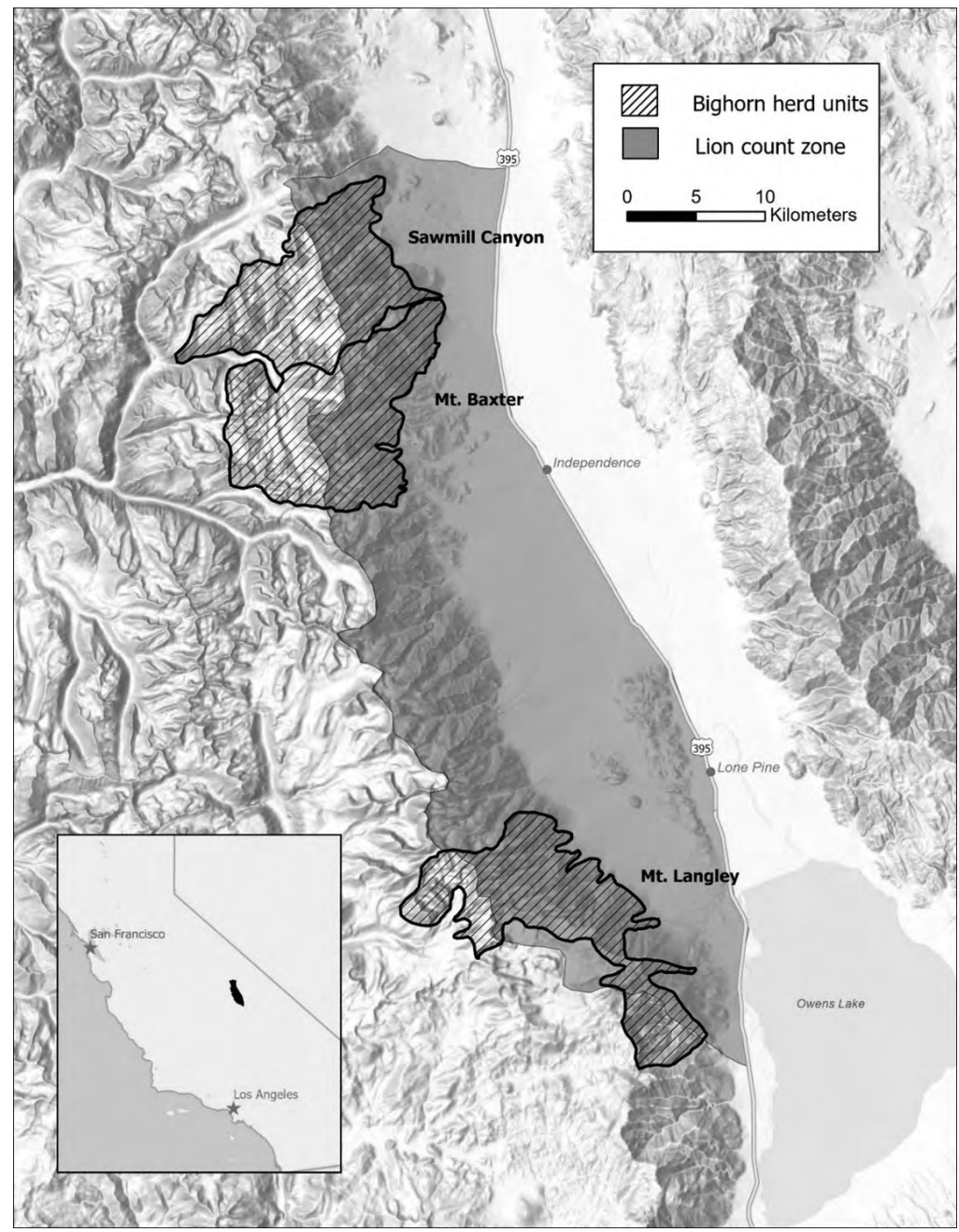

Figure 1. Study area in the eastern Sierra Nevada, California in which Sierra Nevada bighorn sheep and lions were monitored, 1999-2019. 
Translocation of Sierra bighorn is a significant conservation challenge however, because few individuals are available in a given year. First, because Sierra bighorn are a distinct subspecies, there is no alternative translocation source. Second, the Department has established a conservative translocation policy to minimize risk of over harvest (Few et al. 2015), which recommends herds contain least 40 yearling and adult females (hereafter, ewes) before they are eligible as a source of translocation stock, and only 4 herds have reached this threshold. Third, the maximum abundance a single source herd has reached is only 63 ewes, meaning that the number of recruits produced annually remains small. Fourth, as of 2017 the Mt. Langley herd - arguably the most productive Sierra bighorn herd since the recovery program began - can no longer be used as a source of translocation stock following a substantial population decline from 49 ewes in 2016 to 19 ewes in 2019, which is hypothesized to have been caused primarily by a dramatic increase in lion predation during the winter of 2016-2017.

Lion predation is a common cause of mortality in ungulates and often occurs at relatively low and constant rates over time, with minimal impact on prey population dynamics (Laundré et al. 2006; Forrester and Wittmer 2013), but in small populations of bighorn sheep, impacts can be pronounced (reviewed in Rominger 2018). Irruptions in lion predation rates, particularly on small and/or endangered prey populations, can substantially exceed long-term averages in an apparently stochastic manner (Festa-Bianchet 2006) and may be the result of individual "specialist" predators whose dietary selection differs from the population mean (Ross et al. 1997; Logan and Sweanor 2001; Festa-Bianchet 2006; Elbroch and Wittmer 2013; Wittmer et al. 2014). If patterns of lion predation can be predicted, it may facilitate more proactive management of predation risk for Sierra bighorn, thus enhancing their recovery.

The U.S. Fish and Wildlife Service has emphasized the need to attempt to reach recovery goals "as quickly as possible" (USFWS 2007). While there has been some success in using translocation to restore extirpated Sierra bighorn herds, such as the re-establishment of the Wheeler Ridge and Mt. Langley herds, recovery goals for Sierra bighorn will likely be reached most rapidly and reliably through considerably more translocations. Maintaining and increasing the abundance of source herds is a necessary prerequisite for these translocations to occur. One way to grow herds and increase translocation stock is to increase survival rates of ewes. While Sierra bighorn die from a variety of causes, most are not amenable to management action that could mitigate them (e.g., deaths from avalanches associated with severe winters). However, lion predation may be reduced through removal of lions that prey upon Sierra bighorn (e.g., Goldstein and Rominger 2012).

Removal of individual predators that negatively impact populations of prey species can be controversial. Objections to removal arise from questions about its efficacy in some circumstances (e.g., Mosnier et al. 2008; Hurley et al. 2011 but see also Boertje et al. 1996; Lewis et al. 2017) or ethics related to animal rights philosophy in others (e.g., Muth and Jamison 2000; Perry and Perry 2007). The latter reason is particularly relevant to Sierra bighorn because, in California, lions are "specially protected", meaning that sport harvest is not permitted (Fish \& G. Code $§ 4800-4809$ ). While this designation is not based on biological information regarding population abundance or trend (Dellinger and Torres 2020), objections to the removal of lions are frequent and often gain significant media attention, both within California (e.g., Los Angeles Time Editorial Board 2020) and nationally (Vera 2020). Objections such as these underscore the need for decision-makers to have objective scientific evaluation of the efficacy of predator management to aid the recovery of Sierra 
bighorn. Following the listing of Sierra bighorn as an endangered species, the California Legislature recognized the need for predation management and in 1999 amended the Fish $\&$ Game Code to authorize the removal of lions that threatened populations of bighorn sheep in California that were threatened, endangered, candidate, or fully protected (Fish \& G. Code $\S 4801)$.

In this paper, we evaluate the role of lion predation in reducing the availability of translocation stock needed for Sierra bighorn recovery efforts. Our first objective was to test the hypothesis that lion predation impeded the ability of Sierra bighorn herds used as sources of translocation stock to produce surplus animals for translocation during 1999-2019. If lion predation impeded the ability of Sierra bighorn herds to produce surplus animals for translocation, we predicted that lion predation would be a primary cause of mortality and ewe survival rates would be largely a function of lion predation rates. Our second objective was to (1) compare lion abundance and ewe survival and predation rates among years of varying predation levels and (2) test the hypothesis that predation severity was stochastic and unpredictable. If lion predation was stochastic, we predicted there would be no association among different levels of lion predation and different levels of lion abundance. Our third objective was to provide a range of estimated times it could take for the Mt. Langley herd to recover to 40 ewes and thus become a viable source of translocation stock again. Our final objective was to determine if the rates lions have been removed to mitigate Sierra bighorn predation exceeded sustainable harvest guidelines, which could indicate a negative impact to the eastern Sierra lion population.

\section{METHODS}

\section{Study Area}

We conducted this study within and adjacent to three Sierra bighorn herds that have provided translocation stock for the recovery program: the geographically overlapping Sawmill Canyon and Mt. Baxter herds (collectively referred to as the Sawmill-Baxter Complex) and the Mt. Langley herd (Fig. 1). The Sawmill Canyon and Mt. Baxter herds are two of the three herds to be continuously occupied by Sierra bighorn since European settlement and the Mt. Langley herd was established via reintroduction using individuals from the Sawmill-Baxter Complex in 1980, after having been extirpated decades prior. We chose these herds for analysis because each experienced lion predation substantial enough to warrant management intervention (i.e., removal of lions that were known or suspected to have preyed upon Sierra bighorn) and continuous data on lion abundance within and adjacent to the herds was available during our study period (1999-2019). We did not include a fourth source herd, Wheeler Ridge, in this analysis because documented lion predation was heavily biased to rams (California Department of Fish and Wildlife, unpublished data), and therefore of less consequence to the herd's productivity, and because data on lion abundance there was less complete after 2010.

\section{Sierra Bighorn Monitoring}

We began radio-collaring Sierra bighorn in 2002 within the Sawmill-Baxter Complex and in 2003 within the Mt. Langley herd. During 2009-2019, 2000-2019, and 1999-2019 for Sawmill Canyon, Mt. Baxter, and Mt. Langley, respectively, we obtained annual estimates of Sierra bighorn ewe abundance using both minimum counts and mark-resight estimates. 
Years were categorized as biological years (1 May-30 April) unless otherwise stated. Counts of Sierra bighorn within herds that numbered up to $\sim 30$ ewes were generally assumed to be relatively complete (i.e., censuses) and because typically $\sim 30 \%$ of the ewes within a herd were collared at any time, the likelihood of missing large groups of individuals was minimal (Stephenson et al. 2012). We derived mark-resight estimates using the Bowden estimator (Bowden and Kufeld 1995).

Mortalities of uncollared Sierra bighorn were identified via (1) investigation of sites where VHF signals or GPS data indicated radio-collared lions were present for $\geq 2$ consecutive nights, (2) tracking uncollared lions to cache sites, or (3) incidentally to other field work. Mortalities of radio-collared Sierra bighorn were identified via mortality signals from radio-collared individuals. We classified causes of death as lion predation, accident (i.e., injury due to rockfall, avalanche, or other non-predation injury), starvation, natural causes (i.e., old-age, unknown but not predation), other predator (i.e., bobcat [Lynx rufus] or coyote [Canis latrans]), and unknown. Two or more lines of physical evidence (i.e., neck hemorrhaging, lion tracks and/or scat, drag marks, cached remains, plucked hair, clipped ribs, intact rumen) were required to classify mortalities as caused by lion predation.

\section{Lion Population Monitoring}

During 1999-2011 and 2016-2019, we (1) captured, collared, and monitored individual lions residing near Sierra bighorn; (2) determined the minimum number of independent-age (i.e., >18 months old, approximately) lions occurring each year (1 July-30 June) within a "count zone" encompassing the winter range of each Sierra bighorn herd (Fig. 1); (3) hazed or harassed lions to protect sheep when feasible; and (4) lethally removed lions when deemed necessary to protect Sierra bighorn. During all years, annual lion counts were determined by summing the number of marked individuals, unmarked individuals reported dead (e.g., vehicle collisions, depredation killing), and uniquely identifiable unmarked individuals documented via detection at radio-collared Sierra bighorn mortalities as well as through extensive track and trail camera surveys. We used methods adapted from McBride et al (2008) and further described in Davis et al. (2012) to distinguish unmarked individual lions from each other and avoid double-counting, considering detections of unmarked individuals to be distinct if they occurred $>9.6 \mathrm{~km}$ apart for females and $>16.1 \mathrm{~km}$ for males within a $24-\mathrm{h}$ period. When track observations were used to distinguish between unmarked individuals, only tracks $<24$ hrs old were used. Track age was verified by wind, rain, or snow events, or evidence that tracks occurred the night prior to a survey, such as those occurring over vehicle tracks or dragged roads from the previous day. To avoid overestimating lion abundance, we did not reconstruct presumed incomplete counts by assuming that females initially captured when $\geq 30$ months old were born within the study area (e.g., Logan and Sweanor 2001; Robinson et al. 2008). Individuals were only counted when there was direct physical evidence of their presence. This method is widely considered the most reliable way for monitoring lion abundance over time (Cougar Management Guidelines Working Group 2005).

Within the Mt. Langley herd, we had more fine-scale data available to index lion activity. Using the same method to develop annual lion counts, we developed minimum daily counts or "lion days per year" as the minimum number of lion-days annually within the Mt. Langley herd by summing the number of days each marked individual was detected (i.e., GPS or aerial VHF locations, or capture, photograph, visual, or track detections), the number of days each unmarked, uniquely identifiable individual was detected (where each 
detection counted as 1 lion-day), and the number of days each individual was detected at a cached prey site, where a cache site counted as 3 lion-days, as a conservative estimate of handling time (Knopff et al. 2010). In all years except 2013-2015, we conducted extensive track and/or camera surveys to facilitate counting the number of independent-aged lions that used the Mt. Langley count zone and the Mt. Langley herd to ensure that few, if any, individuals remained undetected.

\section{Data Analysis}

We fit time-to-event models to data from radio-marked Sierra bighorn ewes to estimate cause-specific hazard rates for each herd over the 52-week annual cycle. Before fitting models to data, we standardized the week number so that week 1 began on 1 May and week 52 ended on 30 April. The preceding year was then censored at week 52, and the first entry for the following year was set to week 1 (following Sandercock et al. 2011). We left-truncated data because individuals entered the at-risk group during different weeks (Pollock et al. 1989). We right-censored data in cases of collar failure, immigration or translocation of individuals between herds, or when individuals were still alive at the end of the study (i.e., 30 April 2019). In cases in which individuals were subsequently determined to be alive following a previous collar failure, we imputed their final fate based on the last date known alive, following DeCesare et al. (2015). Because of their geographic proximity and small sample sizes within herds, we pooled survival data from the Sawmill Canyon and Mt. Baxter herds (i.e., the Sawmill-Baxter Complex).

We estimated herd-specific annual ewe survival rates using the Kaplan-Meier staggered-entry estimator (Pollock et al. 1989) and cause-specific mortality using the competing-risks nonparametric cumulative incidence function estimator (NPCIFE) (Heisey and Patterson 2006). We implemented the NPCIFE following the methods used by Griffin et al. (2011), which allows for left-truncation and right censoring and partitioned mortality sources into the 5 aforementioned categories. In addition to the lion predation rate calculated via the CIF (hereafter CIFPR), we also calculated a lion predation rate based on simple ratios (hereafter the naïve predation rate, or NPR). For most years, we calculated the NPR by dividing the number of radio-collared ewes killed by lions by the number of radio-collared ewes present. For years prior to the initiation of radio-collaring, we calculated the NPR by dividing the number of uncollared lion-killed ewes detected by the estimate of ewe abundance (using data from Mt. Baxter during 2000-2003, when abundance for Sawmill Canyon was unavailable, to represent the Sawmill-Baxter Complex), which was justified on the basis that these 2 methods of calculating NPR were highly correlated (Pearson's correlation coefficient $=0.94, \mathrm{P}<0.001$ ). There were 2 years for the Mt. Langley herd in which we detected uncollared ewes killed by lions, but no collared ewes killed by lions (2009 and 2018); in these years we calculated NPR by dividing the number of lion-killed ewes by the estimate of ewe abundance. While the NPR suffers a shortcoming over the CIFPR in that it (1) does not account for the staggered nature of animal entry time into interval risk sets and (2) does not permit an estimate of variance (Heisey and Patterson 2006), the advantages of its use are (1) the number of years in which inferences about mortality rates can be made is greater, because it can be calculated even when radio-telemetry data are unavailable and (2) estimates of mortality rates can be made even when only 1 individual dies from a given cause and no individuals die from competing causes prior to that individual's death-in such cases the CIF is undefined. 
To aid evaluation of our first objective, testing the hypothesis that lion predation negatively impacts Sierra bighorn herds used as source of translocation stock and impeded the ability of these herds to produce surplus individuals for translocation, we used linear regression to evaluate the relationship between the CIFPR and NPR with survival rates. This is a widely used method to detect when mortality agents have additive effects on survival (Bender and Rosas-Rosas 2006; Brody et al. 2013; Johnson et al. 2013; Murray et al. 2010; Wolfe et al. 2014). Predation was considered additive if the regression slope $( \pm 95 \% \mathrm{CI})$ of the arcsin-square root of predation and survival rates overlapped -1.0, fully compensatory if the slope $=0.0$, and intermediate slopes were considered partially compensatory (Murray et al. 2010).

For our second objective, to compare lion abundance and ewe survival between years of different predation severity levels, we categorized predation severity into 3 categories for each herd-year: no documented predation (i.e., no lion-killed ewes detected), typical predation (i.e., NPR less than the 90th percentile), and extreme predation (i.e., NPR was greater than or equal to the 90th percentile). To test the hypothesis that predation severity was related to lion abundance, we used a chi-squared test to compare the frequency of herd-years in which each level of predation severity (i.e., none, typical, extreme) occurred during years when $2-5$ or 6-9 lions were counted.

For our third objective, to provide a range of estimated times it could take for the Mt. Langley herd to recover to 40 ewes and thus become a viable source for translocation stock, we calculated the time required by solving for $t$ in the equation

$$
N_{t}=N_{0} e^{r t}
$$

where $N_{t}$ is the population size at time $t, N_{0}$ is the initial population size, $e$ is the base of natural logarithms, $r$ is instantaneous rate of population growth, and $t$ is time. We evaluated return time using a range of growth rates observed during the past 20 years (German and Stephenson 2018; Johnson et al. 2010).

For our final objective, to evaluate how lion removal affected the dynamics of the eastern Sierra lion population, we quantified the fraction of suitable habitat for lions in the eastern Sierra population that was potentially impacted by Sierra bighorn recovery activities by dividing the area of occupied Sierra bighorn habitat, including habitat outside of the Sawmill-Baxter Complex and Mt. Langley herds (i.e., 2,004 $\mathrm{km}^{2}$, determined from herd boundaries used in the Recovery plan, (USFWS 2007), by the area of suitable lion habitat for the eastern Sierra population (i.e., 10,241 $\mathrm{km}^{2}$, from Dellinger et al. 2020). In addition, we estimated a conservative percentage of the eastern Sierra lion population removed annually by dividing the number of independent lions removed by the effective population size $\left(N_{e}\right)$ (i.e., 23, from Gustafson et al. 2019). To evaluate if removal rates exceed sustainable harvest guidelines, we compared the percentage of the eastern Sierra lion population removed annually to a guideline of $14 \%$ that has been used for sustainable harvest management in Washington (Wielgus et al. 2013; Beausoleil et al. 2021) but also thought to be widely applicable throughout the western U.S. (Beausoleil et al. 2013).

\section{RESULTS}

We radio-monitored 158 Sierra bighorn ewes ( $\mathrm{n}=100$ in the Sawmill-Baxter Complex and 58 in the Mt. Langley herd) and 43 lions (18 female; 25 male) that used the count zone 
encompassing these Sierra bighorn herds. These marked animals aided in assessing species demography and trends through time (Fig. 2), which are described below.

\section{9-2005}

Lion counts averaged 3.9/yr and lion predation on Sierra bighorn was not detected until 2005. Two lions, both of which used habitat within the Sawmill-Baxter Complex and Mt. Langley herds and were either known or suspected of killing Sierra bighorn, were re-
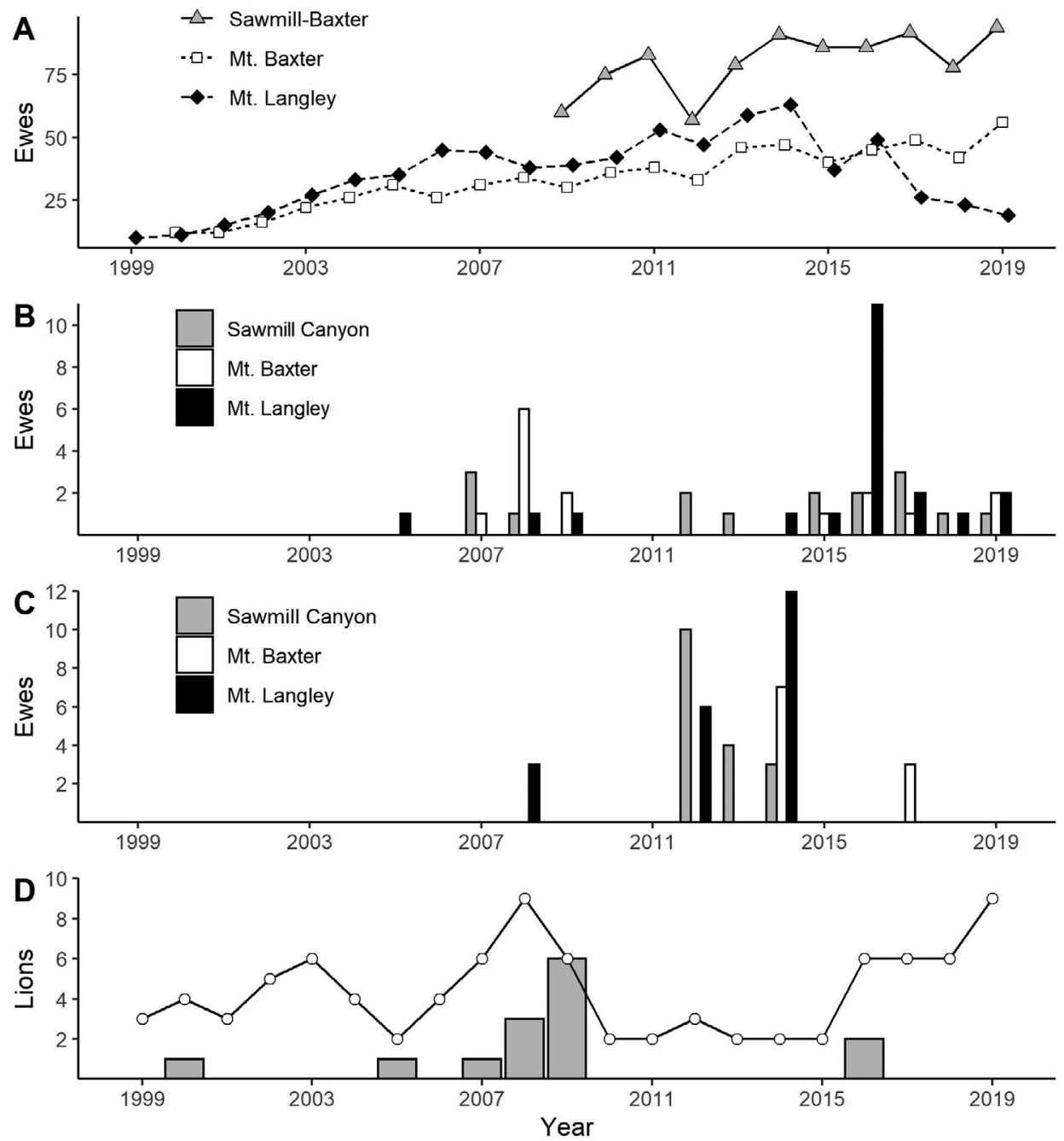

Figure 2. (A) Sierra bighorn ewe abundance, (B) lion-killed ewes detected, both collared and uncollared within the Mt. Baxter, Sawmill Canyon, and Mt. Langley herds, (C) ewes translocated within the Mt. Baxter, Sawmill Canyon, and Mt. Langley herds, and (D) number of independent age lions (i.e., $\geq 18$ months old) counted (circles) and number of lions (i.e., any age) removed (bars) within the lion count zone adjacent to these herds during 1999-2019. Abundance of Sierra bighorn for the Sawmill Canyon herd was unavailable prior to 2009; subsequent to this year abundance for Sawmill Canyon and Mt. Baxter was combined (i.e., Sawmill-Baxter). 
moved (0.3/yr). Both the Mt. Baxter and Mt. Langley herds experienced substantial growth, increasing from $<12$ ewes to $>30$ ewes, although some of the growth in the Mt. Baxter herd was the result of 5 ewes that were translocated into the it from the Wheeler Ridge herd in 2004. Presumably the Sawmill Canyon herd increased as well, but efficient surveys for this herd were not developed until 2009, and thus growth within the Sawmill Canyon herd prior to that year is assumed to correspond with growth of the Mt. Baxter herd. No translocations were conducted during this period because the herds were not yet of sufficient size.

\section{6-2009}

Lion counts steadily increased annually, reaching a peak of 9 in 2008 . The increase in lion counts was associated with elevated predation upon Sierra bighorn, primarily within the Sawmill-Baxter Complex, that had not been documented up to that point, as well as decreases in growth from the previous period for both the Mt. Baxter and Mt. Langley herds. As in the previous period, we assume that growth rates within the Sawmill Canyon herd corresponded with that of the Mt. Baxter herd. In response to the increase in predation, 10 lions (i.e., most of the independent-aged lions within the count zone) were removed during 2007-2009 (3.3/yr), all but one of which were known to have preyed upon Sierra bighorn. In 2008, because the Mt. Langley herd had reached a sufficient number of ewes to permit translocation the year prior $(n=44)$ and had had little previous documented lion predation, 3 ewes were translocated from this herd.

\section{0-2015}

The number of lions counted remained low during this 6-year period (range $=2-3$ ), and lion predation remained relatively infrequent. As Sierra bighorn herds increased in abundance, we translocated 27 ewes from the Sawmill-Baxter Complex (17 ewes from Sawmill Canyon and 10 ewes from Mt. Baxter) and 18 ewes from Mt. Langley to aid in the re-establishment of herds within formerly occupied habitat and augment existing small herds (Table 1). All herds (Mt. Baxter, Mt. Langley, and Sawmill Canyon and Mt. Baxter combined [i.e., the Sawmill-Baxter Complex]) experienced modest growth during this period.

\section{6-2019}

Recolonization of lions occurred during these years and by the end of this period the number of lions counted recovered to the former peak of 9 that was observed during 2008. Elevated predation upon Sierra bighorn resumed during this period as well, most notably during 2016, when the NPR and CIFPR at Mt. Langley were 0.42 and 0.47 , respectively. In response, 2 of the 7 lions known to be using the Mt. Langley winter range were removed; an adult male and an adult female with at least 3 subadults (all uncollared animals) were unable to be removed. Modest growth within the Sawmill-Baxter Complex continued and the Mt. Langley herd declined in abundance from 49 females in 2016 to 19 females in 2019. Given the amount of lion predation that occurred during this time and concern about a combination of lion predation and translocation resulting in excess losses to source herds, we conducted only a single translocation of 3 ewes from the Sawmill-Baxter Complex (Mt. Baxter) in 2017. 
Table 1. Translocations of Sierra bighorn ewes from the Mt. Baxter, Sawmill Canyon, and Mt. Langley herds during 2012-2014.

\begin{tabular}{lclcl}
\hline Source Herd & Year & Recipient Herd & No. Ewes & Translocation purpose \\
\hline Sawmill-Baxter Complex & 2012 & Olancha Peak & 10 & Reintroduction \\
& 2013 & Olancha Peak & 4 & Augmentation \\
& 2014 & Laurel Creek & 7 & Reintroduction \\
& 2014 & Mt. Gibbs & 3 & Augmentation \\
& 2008 & Mt. Warren & 3 & Augmentation \\
Mt. Langley & 2012 & Convict Creek & 3 & Augmentation \\
& 2012 & Mt. Gibbs & 3 & Augmentation \\
& 2014 & Cathedral & 10 & Reintroduction \\
& 2014 & Mt. Gibbs & 2 & Augmentation \\
\cline { 2 - 4 } & Total & 48 & \\
\hline
\end{tabular}

\section{Cause-Specific Mortality and Survival}

We calculated annual survival and cause-specific mortality rates for the Sawmill-Baxter Complex in 2004-2019 and Mt. Langley in 2003-2019 (Table 2). There was one year (2003) for the Mt. Langley herd in which only 3 ewes were at risk, otherwise the mean number of radiomarked ewes annually was 25.2 for the Sawmill-Baxter Complex (range =9-44) and 14.8 for Mt. Langley (range = 8-23). Over 35\% of each herd was radio-marked each year, on average (range $=11.1-57.9 \%$ ). Across the Sawmill-Baxter Complex and Mt. Langley, the mean CIFPR was 0.06 (range $=0-0.47, \mathrm{n}=33$ ) and the mean NPR was 0.05 (range $=$ $0-0.42, \mathrm{n}=42$ ). Herd-years in which the NPR was $>0.11$ were in the 90 th percentile and considered to be years of extreme predation (Fig. 3). In $73.8 \%(n=31)$ of herd-years, the NPR was based solely on radiomarked individuals.

We investigated the mortalities of 78 radiomarked Sierra bighorn ewes $(n=47$ in the Sawmill-Baxter Complex and $n=31$ in the Mt. Langley herd) between 2003 and 2019. Lion predation was the dominant cause of mortality, accounting for $48.7 \%$ of all deaths investigated ( 38 of 78 deaths) and $70.1 \%$ of the deaths in which the cause could be determined ( 38 of 54 deaths; Fig. 4). Accidents (i.e., deaths from avalanches and rockfall, hypothermia, and physical injury) were the second-most common known cause of mortality. Sierra bighorn ewes were 3.3 times and 5.0 times more likely to die from lion predation than accidents in the Sawmill-Baxter Complex and Mt. Langley, respectively. We also documented lion predation of 14 uncollared ewes (Fig 2).

When annual survival rates from each herd were regressed against their respective annual predation rates, the relationship was highly correlated within both the Sawmill-Baxter Complex and Mt. Langley for each method of calculating predation rates (i.e., NPR and CIFPR; Fig. 5). Regression slopes for annual survival within the Sawmill-Baxter Complex for NPR (slope: $-1.23(-1.58,0.88), \mathrm{t}_{14}=36.09, \mathrm{P}<0.001, \mathrm{R}_{\text {adj }}^{2}=0.76$ ) and CIFPR (slope: $\left.-1.05(-1.39,0.70), \mathrm{t}_{14}=33.73, \mathrm{P}<0.001, \mathrm{R}_{\text {adj }}=0.70\right)$ and within Mt. Langley for NPR (slope: $\left.-0.88(-1.28,0.48), \mathrm{t}_{15}=26.0, \mathrm{P}<0.001, \mathrm{R}_{\text {adj }}{ }^{2}=0.52\right)$ and CIFPR (slope: $-0.84(-1.21,0.47)$, $\left.\mathrm{t}_{15}=29.90, \mathrm{P}<0.001, \mathrm{R}_{\text {adj }}^{2}=0.54\right)$ consistently indicated that lion predation was largely an additive source of mortality for Sierra bighorn within these herds. 


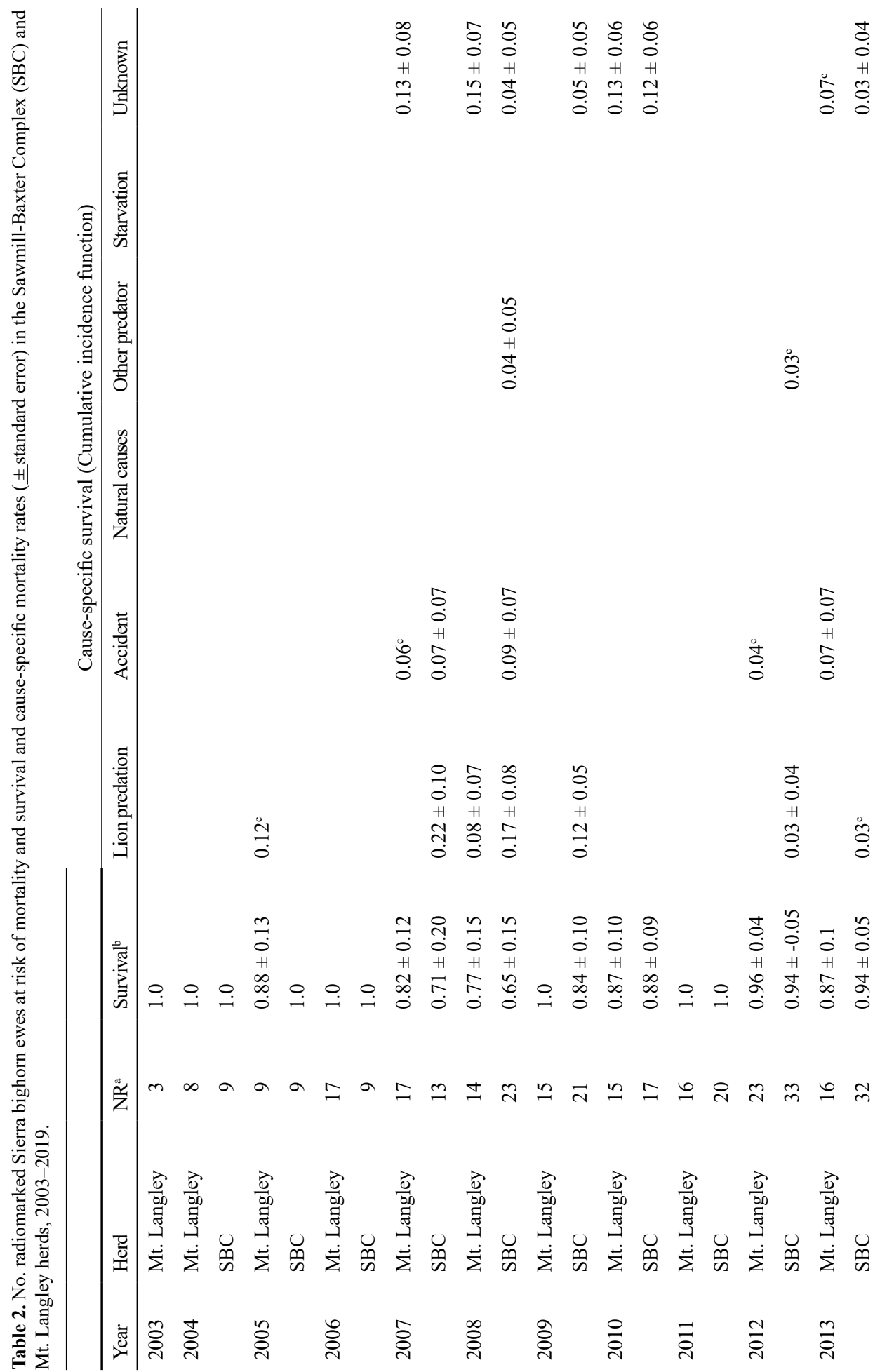




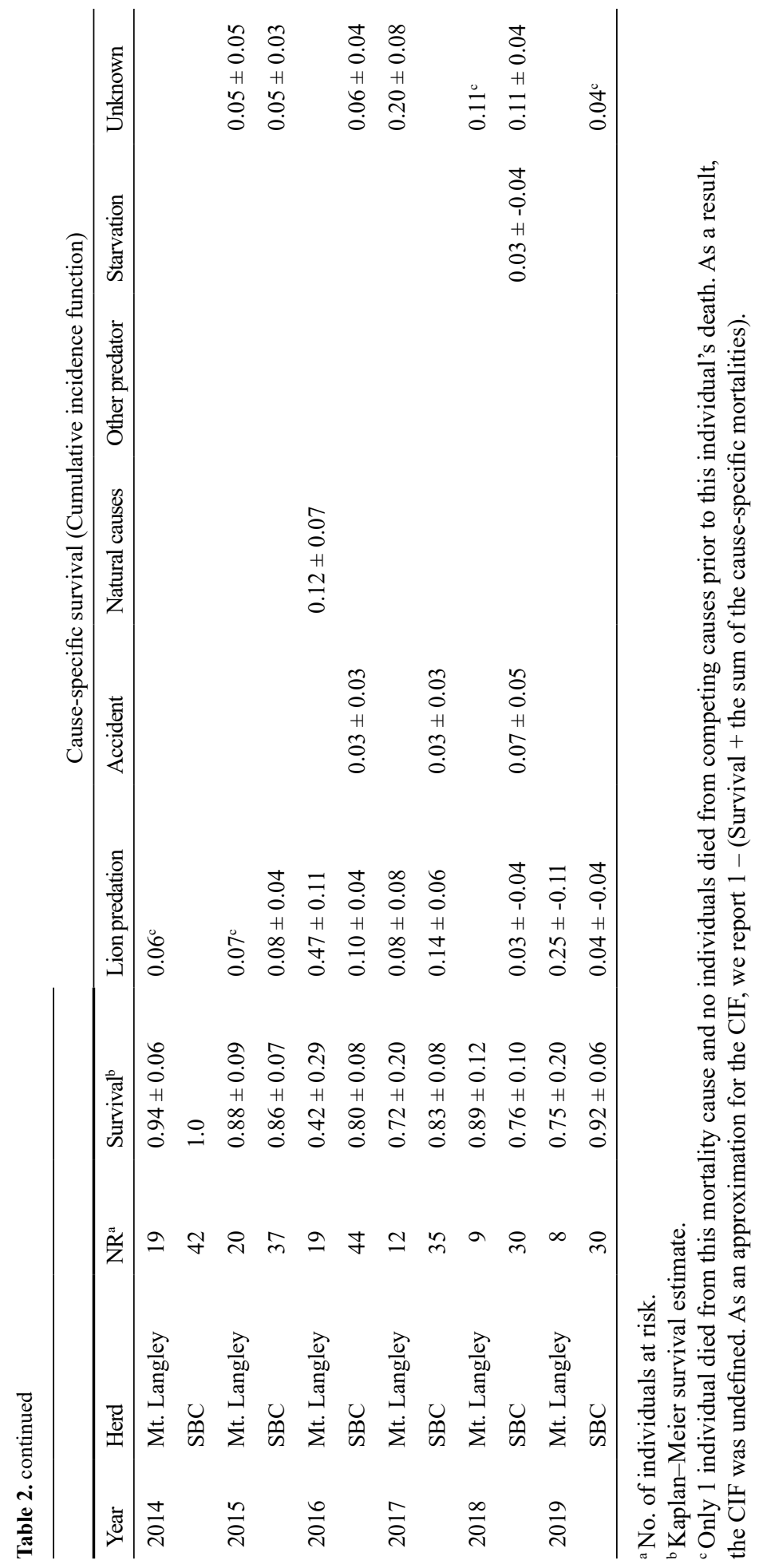




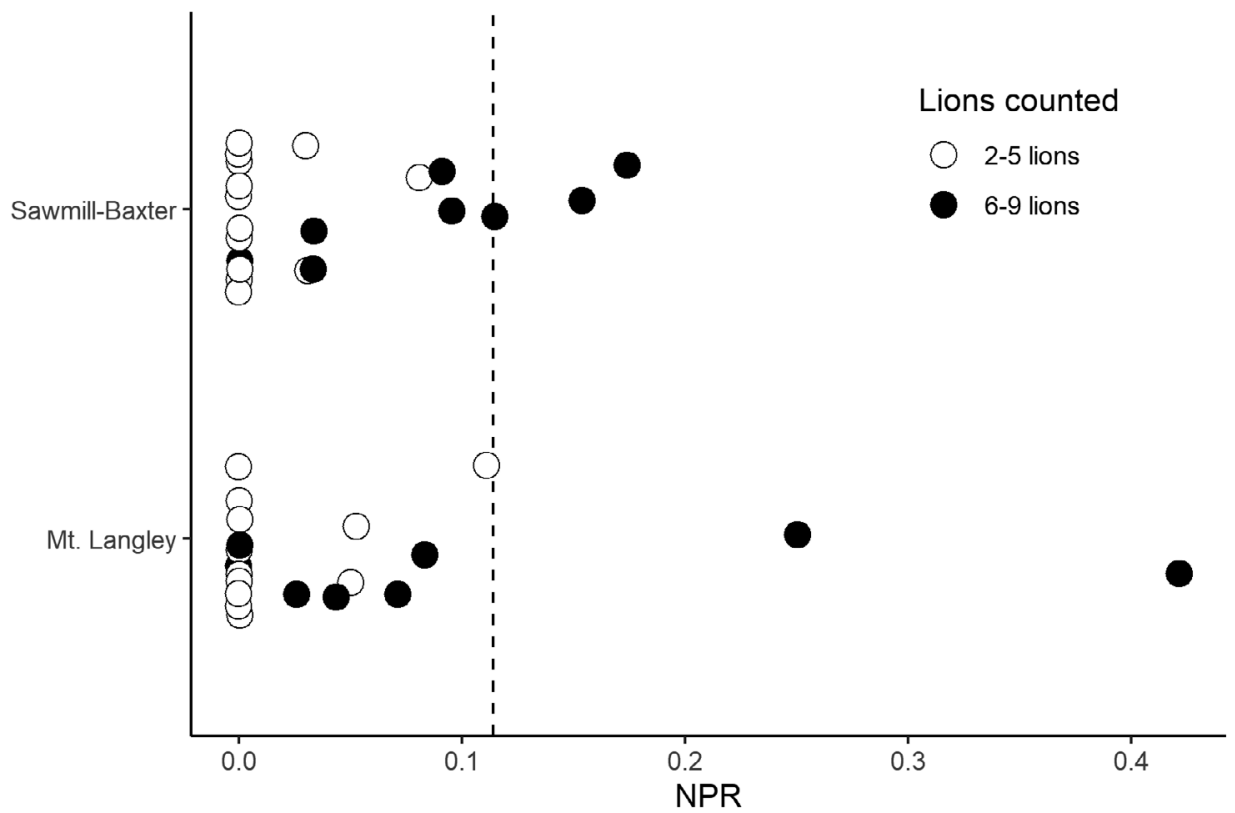

Figure 3. Distribution of annual naïve predation rate (NPR) within the Sawmill-Baxter Complex (2004-2019) and Mt. Langley (1999-2019) Sierra bighorn herds. Vertical dashed line represents the 90th percentile of the NPR.

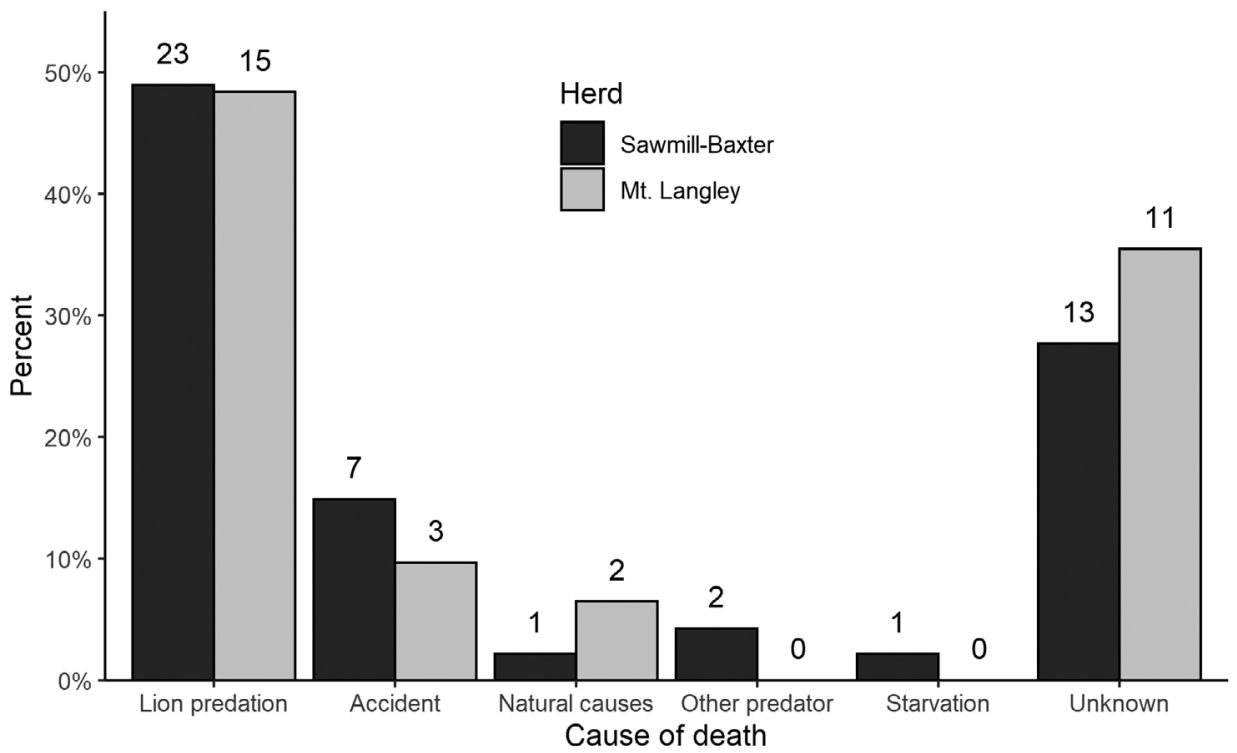

Figure 4. Fates (\%) of 78 radio-collared Sierra bighorn ewes within the Sawmill-Baxter Complex and Mt. Langley herd, 2003-2019. Numbers above bars are total deaths. 


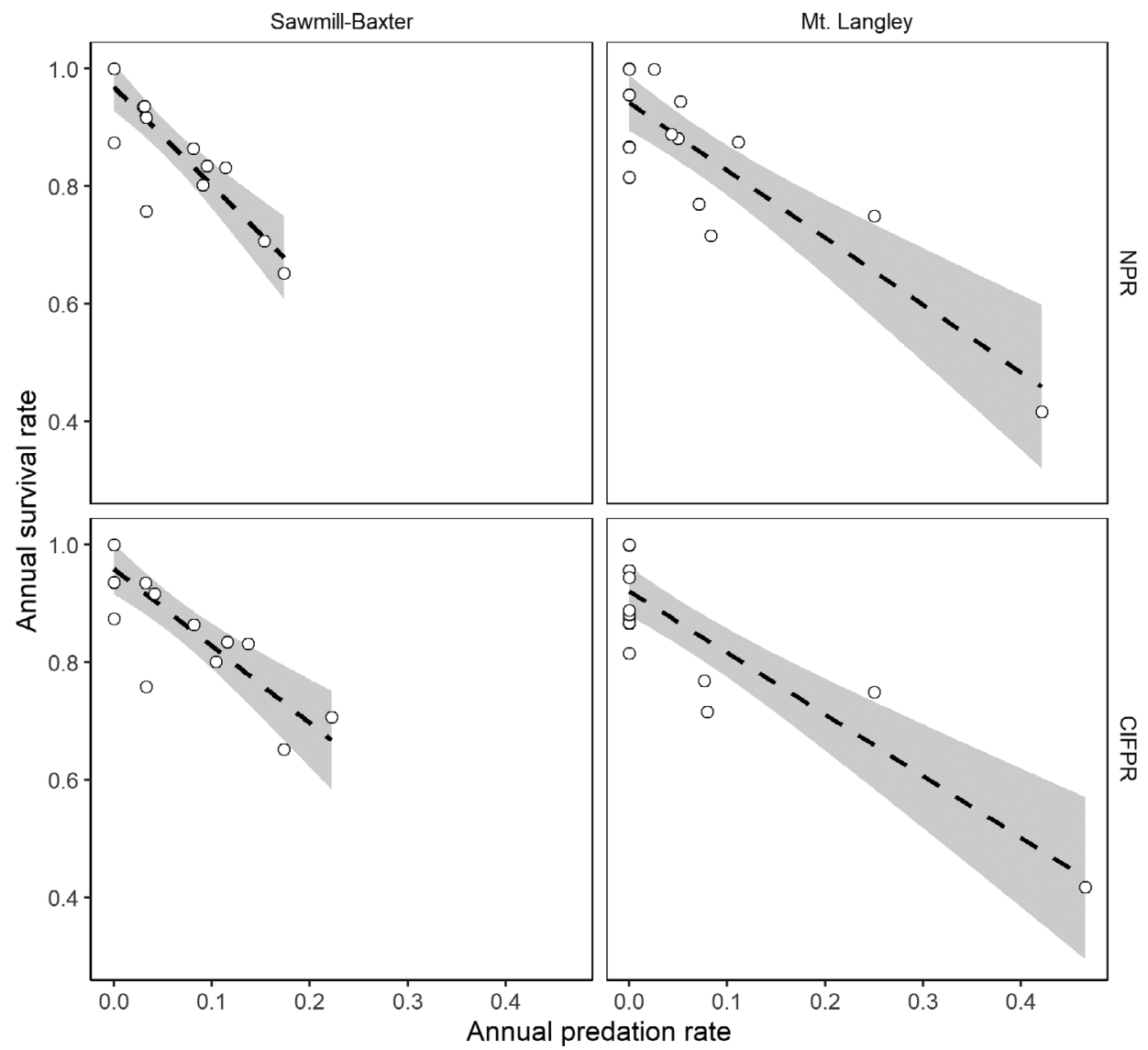

Figure 5. Relationship between annual naïve lion predation rates (NPR) and annual ewe survival rates (top 2 panels) and annual cumulative incidence function-derived lion predation rates (CIFPR) and annual ewe survival rates (bottom 2 panels) for the Sawmill-Baxter Complex and Mt. Langley Sierra bighorn herds, 2003-2019.

\section{Variation in Predation Intensity}

In most years, lion predation was not detected within the Sawmill-Baxter Complex $(52.4 \%$ of years, $n=11)$ or Mt. Langley $(57.1 \%$ of years, $n=12)$. Extreme predation (i.e., when the NPR was $\geq 0.11$ ) occurred in $14.3 \%$ of years in the Sawmill-Baxter Complex (during 2007, 2008, and 2017) and in 9.5\% of years at Mt. Langley (during 2016 and 2019).

In the Sawmill-Baxter Complex, ewe survival during years of extreme predation $(0.73$ $\pm 0.05)$ was $17.8 \%$ less than during years of normal predation $(0.86 \pm 0.03)$ and $34.2 \%$ less than during years of no documented predation $(0.98 \pm 0.02$; Fig. 6$)$. The CIFPR during years of extreme predation $(0.18 \pm 0.02)$ was 3.0 times greater than during years of normal predation $(0.06 \pm 0.02)$ and NPR exhibited a similar pattern (Fig. 6). The lion count during years of extreme predation $(7.0 \pm 1.0)$ was 1.44 times greater than during years of normal predation (4.86 \pm SE 0.99$)$ and 2.08 times greater than during years of no documented predation (3.36 \pm 0.41 ; Fig. 6 ). 
A
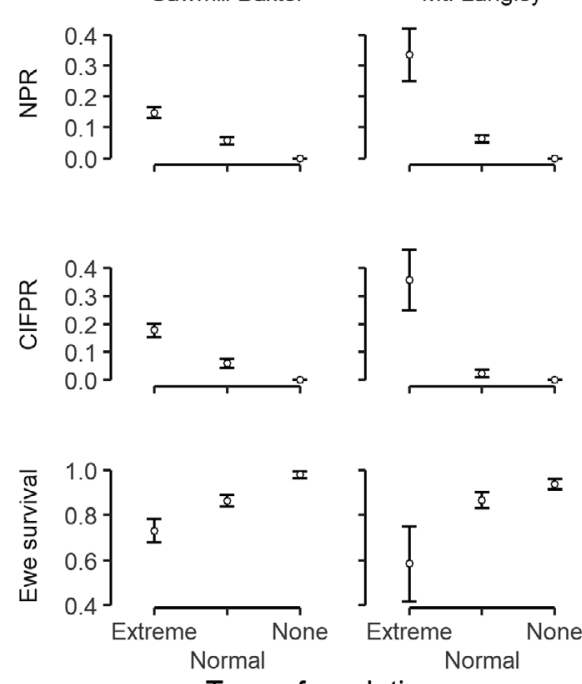

Type of predation year

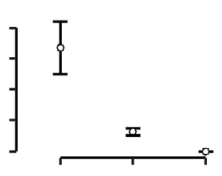

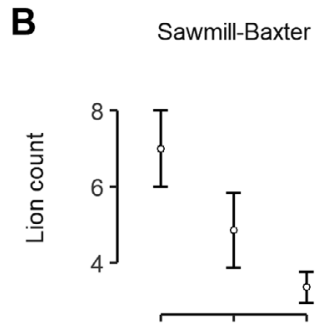

Mt. Langley

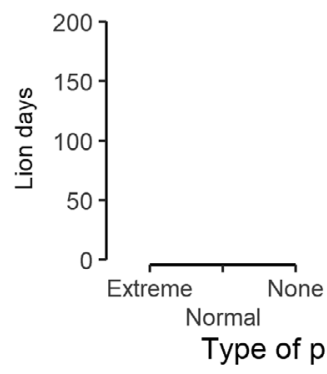

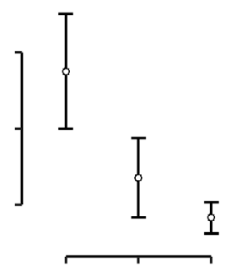

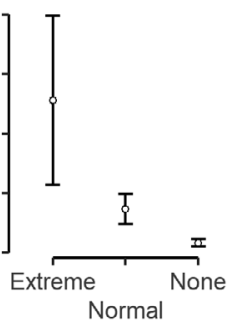

edation year

Figure 6. Mean $( \pm \mathrm{SE})$ naïve predation rate (NPR), cumulative incidence function predation rate (CIFPR) ewe survival, lion counts, and lion-days for the Sawmill-Baxter Complex and Mt. Langley Sierra bighorn herds during years of extreme (NPR greater than or equal to the 90th percentile), normal (NPR less than the 90th percentile), and no lion-predation. Lion-days were not evaluated for the Sawmill-Baxter Complex.

At Mt. Langley, average ewe survival during years of extreme predation $(0.58 \pm 0.02)$ was $50.0 \%$ less than during years of normal predation $(0.87 \pm 0.04)$ and $62.1 \%$ less than during years of no documented predation $(0.94 \pm 0.02$; Fig. 6$)$. The CIFPR during years of extreme predation $(0.36 \pm 0.11)$ was 18.0 times greater than during years of normal predation $(0.02 \pm 0.01)$ and NPR exhibited a similar pattern (Fig. 6). The lion count during years of extreme predation $(7.50 \pm 1.50)$ was 1.59 times greater than during years of normal predation $(4.71 \pm 1.04)$ and 2.04 times greater than during years of no documented predation $(3.67 \pm$ 0.41 ; Fig. 6). The number of lion-days detected during years of extreme predation (128.0 $\pm 71.0)$ was 3.49 times greater than during years of normal predation $(36.71 \pm 12.61)$ and 15.50 times greater than during years of no documented predation $(8.25 \pm 2.95)$.

The frequency in which the 3 levels of predation severity occurred varied over the 2 levels of lion abundance (i.e., $2-5$ and $6-9$ lions; $\chi^{2}=16.4$, $\mathrm{df}=2, \mathrm{P}<0.001$ ). When $2-5$ lions were counted, extreme predation did not occur at all and no documented predation occurred in 20 of 26 (76.9\%) herd-years. In contrast, extreme predation occurred when 6-9 lions were counted in 5 of $16(31.2 \%)$ of herd-years and no documented predation occurred in 3 of $16(18.8 \%)$ herd-years. Typical predation was also more common when the lion count was $6-9(50 \%$ of herd-years) versus $2-5(23.0 \%$; Fig. 3$)$.

\section{Recovery Times for the Mt. Langley Herd}

We estimated the time required for a herd of 19 females (i.e., the number present in 2019 ) to recover to 40 (i.e., the number required to be considered a source of translocation stock again) would be 37.2, 14.9, 7.4, and 3.7 years for growth rates (r) of 0.02, 0.05, 0.1, and 0.2 , respectively. 


\section{Impacts of Lion Removal on the Lion Population}

Based on estimates of the area of occupied Sierra bighorn habitat and suitable lion habitat for the eastern Sierra lion population $\left(10,241 \mathrm{~km}^{2}\right.$, from Dellinger et al. (2020), we estimated that $19.6 \%$ of the suitable habitat for the eastern Sierra lion population overlaps with occupied Sierra bighorn habitat and 3.8\% overlaps with habitat occupied by the SawmillBaxter Complex and Mt. Langley herd, where both lion predation and lion removal has been most prominent relative to other Sierra bighorn herds. During 1999-2019, we removed 26 lions to protect Sierra bighorn (i.e., 11 independent and 3 dependent lions to protect Sierra bighorn in the Sawmill-Baxter Complex and Mt. Langley herds; 9 independent and 3 dependent lions to protect other herds). The number of independent lions removed annually averaged 0.95 (range $=0-5)$, corresponding with an estimated annual removal rate of $4.14 \%$ (range $=0-21.7 \%$ ) of the eastern Sierra lion breeding population, based on the $N_{e}$ estimate of 23 lions from Gustafson et al (2019).

\section{DISCUSSION}

\section{Cause-Specific Mortality and Survival}

Lion predation has been a management concern for the recovery of Sierra bighorn for decades and was a primary reason for listing Sierra bighorn as endangered (Wehausen 1996; USFWS 1999, 2007). We sought to evaluate the role of lion predation in the recovery of Sierra bighorn, including how lion predation may contribute to a shortage of translocation stock that is needed for the recovery effort. Our results indicated that lion predation limited the number of ewes available for translocation within the Sawmill-Baxter Complex and Mt. Langley herds during 1999-2019 by removing a substantial number of ewes in these source herds that could otherwise have served as translocation stock. Approximately half of all radiomarked ewe deaths (38 of 78), and potentially more given the high proportion of mortalities whose cause could not be identified, were the result of lion predation. Further, annual survival rates of ewes decreased substantially as lion predation rates increased, indicating that lion predation was primarily additive to other sources of mortality (e.g., Johnson et al. 2013; Bowyer et al. 2014). Because animals lost to predation are not available for translocation, which is a critical component of the recovery program, we conclude that lion predation has impeded recovery of Sierra bighorn throughout the recovery program's duration. Continued unmitigated predation at rates similar to observed 2016-2019 rates remain a substantial management concern, which if not addressed, could contribute to the extirpation of Sierra bighorn herds. Lion predation is an immediate threat to the viability of the depressed Mt. Langley herd.

Our findings are consistent with those from Johnson et al. (2013) that lion predation is an additive source of mortality within the Sawmill-Baxter Complex. However contrary to Johnson et al. (2013), we found lion predation was also an additive source of mortality within the Mt. Langley herd. This discrepancy is because our 17-year dataset included greater variation in survival and predation compared to the five-year dataset examined by Johnson et al. (2013). The contrasting results between these studies illustrate the importance of long-term monitoring, which can uncover patterns in data and important management implications that may be missed in shorter-term studies (Lovett et al. 2007).

Previous studies of Sierra bighorn provide additional evidence that supports our conclusion that lion predation was an additive cause of mortality, impeding the ability of source 
herds to produce translocation stock. For example, population size was in none of the top models used by Conner et al. (2018) to explain variation in adult survival during 2002-2013, and most ewes during 2002-2018 had body fat levels well above the physiological minimum required for overwinter survival (Stephenson et al. 2020). Notably, out of 11 different herds examined, the Mt. Langley herd had some of the highest average body fat measurements recorded (Stephenson et al. 2020). If predation was primarily a compensatory cause of mortality (i.e., lions preyed upon individuals that likely would have died from another cause in the absence of predation), such findings would not be expected (Bowyer et al. 2014).

We calculated predation rates using two different methods, producing a NPR and CIFPR, which were remarkably similar to each other. However, while the methods of Heisey and Patterson (2006) for estimating CIFs are widely used (e.g., Murray et al. 2010; Griffin et al. 2011; Sandercock et al. 2011), in small populations such as ours, CIFs may have limited value if solely relied upon for inferring the importance of different mortality sources. For example, several cause-specific mortality rates in Table 2 were undefined because only 1 individual died from a given mortality cause during a year and no individuals died from competing causes prior to that individual's death. In addition, had we relied on the CIFPR alone, which uses only data from radio-marked animals, during 2009 and 2018 when $\sim 40 \%$ of ewes in the Mt. Langley herd were radio marked and none died from lion predation, we would have inferred that lion predation was unimportant, even though we knew that at least 1 uncollared ewe was killed each year, representing $2.5 \%$ and $4.3 \%$ of the herd, respectively. These examples illustrate that in small, endangered populations like Sierra bighorn, where the death of even single individuals can be consequential, it may be useful to use simple ratio estimators for cause-specific mortality in addition to more statistically robust ones. These examples also illustrate the importance of maintaining radio-collars on as many lions as possible in Sierra bighorn habitat because predation can go unnoticed even with a substantial fraction of Sierra bighorn being collared. Maintaining radio-collars on lions would also aid in targeting management responses to only those that prey upon Sierra bighorn, which may help promote tolerance of lethal removal among stakeholders.

\section{Variation in Predation Intensity}

When comparing Sierra bighorn ewe survival among years of extreme, typical, and no documented predation we found that during years of extreme predation ewe survival rates were poor, averaging 0.73 and 0.58 in the Sawmill-Baxter Complex and Mt. Langley herds respectively, values which resulted in population declines in those years. However, even during years of typical predation, average ewe survival rates in the Sawmill-Baxter Complex and Mt. Langley herd were 0.86 and 0.87 respectively, which are near the threshold needed for population stability, assuming recruitment rates remain within their historic range of variability (Few et al. 2015), but below a value needed to ensure population growth and ultimately recovery and delisting. Thus, typical predation, if not punctuated by years without predation could, especially in combination with other mortality sources, prevent population growth (e.g., Harris et al. 2009). Because other causes of mortality are relatively rare compared to lion predation (Fig. 4) and are not as amenable to management intervention as lion predation, there are few options for improving Sierra bighorn survival outside of lion removal. During this study, all lion removal was lethal, and it is likely that lethal removal will need to be an option in the future if Sierra bighorn survival rates are to be improved. However, it may be possible in limited circumstances to experiment with non-lethal removal 
as well (i.e., translocating lions to areas away from Sierra bighorn), which could be viewed as more favorable by some stakeholders. There are numerous factors to be considered with translocation that are not present with lethal removal, including (1) the logistical difficulty in carrying large animals from remote, roadless areas to transport vehicles, which involves measurable risks for both project personnel and animals involved, (2) extended times (perhaps many hours) that animals must be under anesthesia, (3) nonestablishment, resulting in movements that bring animals into human-wildlife conflict or homing that brings them back into contact with Sierra bighorn, and (4) animal welfare concerns associated with intraspecific strife at release sites, disorientation at release sites that inhibits the ability to locate prey and/or shelter, or increased exposure to hazards, such as highways (e.g., see Craven et al. 1998). There has been very limited research on lion translocation to date (i.e., Ruth et al. 1998 is the only study of which we are aware that has tracked the fates of translocated lions) and thus, there is more speculation about potential outcomes than available data. Nonetheless, translocation of lions has been used successfully for conservation purposes, such as improving the genetics of the endangered Florida panther (Puma concolor coryi; van de Kerk et al. 2019). Given that several lion populations in southern CA are of conservation concern and have been petitioned for listing under the CA Endangered Species Act (Center for Biological Diversity and the Mountain Lion Foundation 2019) because of similar issues experienced by Florida panthers (Gustafson et al, 2017; Benson et al. 2019; Gustafson et al. 2019), translocation of lions to southern CA populations, as suggested by Benson et al. (2019), from the eastern Sierra Nevada may be an option that could benefit 2 at risk species (Sierra bighorn and southern CA lions) simultaneously.

Episodes of unusually high predation rates have been reported for Sierra bighorn previously, including in the Mt. Warren herd in the early 1980s (Chow 1992) and in the Sawmill-Baxter Complex in the 1990s (Wehausen 1996). Such periods of apparently stochastic changes in the frequency of lion predation upon rare prey have been documented elsewhere as well, such as bighorn sheep in Alberta (Festa-Bianchet et al. 2006) and endangered huemul (Hippocamelus bisulcus) in Patagonia (Elbroch and Wittmer 2013; Wittmer et al. 2014). The leading hypothesis to explain such irruptions in predation is that they are caused by stochastic changes in the composition of a lion population (e.g., death or immigration), combined with variation in dietary choices between individual lions - factors that are independent of lion abundance (Ross et al. 1997; Logan and Sweanor 2001). Based on our findings that severe predation did not occur when lion counts were relatively low (2-5 lions) but did occur in 50\% of the years when lion counts were high (6-9 lions), and that on average our two indices of lion abundance (i.e., counts) and activity (i.e., lion-days) were progressively greater in years of no documented predation, typical predation, and severe predation respectively (Fig. 5), we do not consider lion predation on Sierra bighorn to be primarily a stochastic phenomenon. Rather, episodes of extreme predation are somewhat predictable, and provided that monitoring of lion abundance continues, advance warning of extreme predation years can be available. However, because we did not evaluate lion diet selection or estimate prey availability, we cannot exclude the possibility that specialist lions were present in some years. Increased predation in association with increases in lion abundance could be explained by the increased odds of lions encountering relatively rare Sierra bighorn while hunting their primary mule deer (Odocoileus hemionus) prey (Pierce et al. 1999, 2000), an increase in the odds that at least one lion selectively preyed upon Sierra bighorn, or both. 


\section{Recovery Times for the Mt. Langley Herd}

The Mt. Langley herd declined substantially during its extreme predation episode and if the pattern of decline observed from 2016-2019 continues, this herd will become extirpated within a few years. Lion-mediated extirpations of bighorn sheep have been documented elsewhere. For example, Rominger et al. (2004) reported that a bighorn sheep translocation effort in the Sierra Ladron mountains of New Mexico failed primarily because of lion predation, noting that as the bighorn population declined, the predation rate actually increased, which they suspected to be the result of lions being subsidized by domestic cattle. Similarly, the functional extirpation of a herd of desert bighorn (i.e., only a single ewe remained at the end of the study) in the San Andreas Mountains of New Mexico occurred when lions killed most of what was left of a herd of nine bighorn in a span of less than a year (Rominger and Weisenberger 2000).

The Mt. Langley herd currently is not a viable source of translocation stock, a change that has reduced the Recovery Program's capacity for translocation by about $25 \%$ (i.e., of 73 ewes translocated during 2004-2019, 21 were removed from the Mt. Langley herd). Consecutive years of predation are likely to have a more negative impact on population growth than years interspersed with a lack of predation, even if the overall predation rate remains the same (Pike et al. 2004; Festa-Bianchet 2006). Given its current low abundance, the Mt. Langley herd is unlikely to rebound to its former abundance in a short time frame unless predation is - at least temporarily - sharply reduced. We calculated that it would take $\sim 15$ years for the 2019 population of 19 ewes to return to 40 ewes if modest population growth (5\% per year) occurs. However, our simple model assumed exponential growth and that lambda is always positive, neither of which may be reasonable assumptions. Whether or not the Mt. Langley herd will recover at all is currently unclear and it may take a substantial amount of time because actual population demographics include stochastic effects (e.g., severe winters) not accounted for in our simple model. On the other hand, high population growth had been documented in the past (e.g., the Mt. Langley herd increased from 10 to 45 ewes during 1999-2006) during a period of favorable weather conditions and almost no lion predation, which provides some reason for optimism. To be clear though, because lion abundance is almost certainly not maintained by Sierra bighorn but by their primary prey, mule deer, the decline in abundance of Sierra bighorn at Mt. Langley is unlikely to appreciably impact the lion population (Pierce et al. 2000; Johnson et al. 2013). Thus, continued high lion predation could drive this herd to extirpation, similar to apparent competition situations that occur among caribou (Rangifer tarandus), moose (Alces alces), and wolf (Canis lupus) populations in Canada (e.g., Serrouya et al. 2015).

In contrast to the Mt. Langley herd, the Sawmill-Baxter Complex performed very differently following the extreme predation episode that occurred there during 2007 and 2008 , experiencing population growth in the years immediately afterward. We suggest that the reason for these divergent trajectories is primarily related to the different management responses that occurred to mitigate the predation. Removal of lions that preyed upon Sierra bighorn within the Sawmill-Baxter Complex began during the predation episode, which likely limited the number of ewes killed, while removing lions that preyed upon Sierra bighorn at Mt. Langley occurred only after $\sim 40 \%$ of the herd had been killed. In addition, during the Sawmill-Baxter Complex extreme predation episode, all of the lions known to prey upon Sierra bighorn within the herd were removed, while during the Mt. Langley extreme predation episode, an adult male and an adult female with at least 3 subadults (all uncollared 
animals) were unable to be removed and may have continued preying upon Sierra bighorn. These observations demonstrate that if predation is to be mitigated through lion removal, quick response times (e.g., beginning tracking and capture efforts within 24-48 hours after a Sierra bighorn kill is confirmed) are required.

\section{Impacts of Lion Removal on the Lion Population}

In response to elevated predation within the Sawmill-Baxter Complex during 20072009 , most independent-aged lions within the count zone were removed. All but one of the lions removed during this period were known to have preyed upon Sierra bighorn. Following lion removals from 2007-2009, lion occupancy in the count zone during 2010-2015 was reduced. During this period, 45 ewes from the Sawmill-Baxter Complex and Mt. Langley herds were translocated to re-establish several previously extirpated herds (Fig. 2; Table 1) - an opportunity that was facilitated by releasing bighorn populations from lion predation. However, the number of lions using Sierra bighorn habitat adjacent to these source herds recovered from a low of two independent lions in 2010-2011 following the period of intense removal to six individuals by 2016, and by 2019 there were as many lions counted $(\mathrm{n}=9)$ as at any point since monitoring began. Rapid recolonization by lions may have been possible because the area from which lions were removed was small relative to the entire eastern Sierra lion population, which functions as a source population (Gustafson et al 2019), and/or because of connectivity between the eastern Sierra lion population and western Sierra Nevada and North Coast lion populations of CA as well as the Nevada lion population which exchange migrants in both directions (Gustafson et al. 2019). Such rapid recolonization of vacant lion habitat suggests long-term negative impacts to the number and distribution of lions in the eastern Sierra lion population from removals to protect Sierra bighorn from predation are unlikely. This observation is consistent with our estimate that the majority $(>80 \%)$ of the suitable habitat for the eastern Sierra lion population does not overlap Sierra bighorn habitat, indicating that a substantial fraction of the lion population is not subject to removal because those lions do not interact with Sierra bighorn, and (2) the average level of lion removals to date $(0.95 / \mathrm{yr})$ equates to $4.14 \%$ of the estimated genetically effective population $\left(N_{e}\right)$ of 23 eastern Sierra lions (Gustafson et al. 2019), less than $1 / 3$ of the $14 \%$ sustainable harvest threshold needed for population stability advocated by Beausoleil et al. (2013), Wielgus et al. (2013), and Beausoleil et al. (2021). Should lion removal rates exceed 3 independent lions/yr, short-term reductions in the eastern Sierra lion population may occur. However, given that numerical abundance is typically considerably higher than $N_{e}$ (Frankham 1995), true removal rates are likely considerably lower than worst case estimates we present based on $N_{e}$. In order to cause a reduction in the eastern Sierra lion population, lion removals for Sierra bighorn protection would almost certainly have to increase substantially over any numbers observed to date.

\section{Conclusion}

Lion predation on Sierra bighorn impeded recovery of Sierra bighorn during 19992019. Uncontrolled lion predation can contribute to poor population performance, even at typical levels, however, extreme levels of predation appear capable of extirpating Sierra bighorn herds and could seriously inhibit recovery of the subspecies. Because lion predation can be intense enough to cause declines in the largest of Sierra bighorn herds, the entire Sierra bighorn population should be considered susceptible to this phenomenon, even within 
herds that have not experienced substantial predation since the Recovery Program began. Our results, combined with the findings of previous work, indicate that years of extreme predation might be expected to occur in approximately 1 of every 10 years in some portion of Sierra bighorn range. However, our observations included years following active predator management (2010-2015) in which the number of lions using Sierra bighorn habitat was substantially reduced. Should predator management not occur in the future, it seems probable that extreme predation events could become more common (and consequently, no longer be considered extreme, in the sense of deviating from the average). Removal of lions that prey upon Sierra bighorn appears to have been effective at improving ewe survival rates and thus using lethal or non-lethal means (e.g., translocation) to remove lions from Sierra bighorn habitat in the future appears necessary if Sierra bighorn are to be recovered. Although we did not have data on cause-specific mortality of neonate Sierra bighorn, lion predation can be a common cause of mortality for neonate desert bighorn (Parsons, Z.D. 2007; Cain et al. 2019); thus, it is possible that lion removal would result in improved recruitment rates as well, which would further accelerate recovery. If such steps are taken, lion abundance within the areas from which lions are removed will almost certainly recover within a short period of time.

While there is a desire within the Department to accommodate natural processes, such as predation, there are currently not enough Sierra bighorn within these herds to simultaneously satisfy the demands of predators and the need to recover this endangered species. High levels of lion predation on Sierra bighorn have already slowed progress toward meeting recovery goals, and if they go unchecked, they could result in the extirpation of entire Sierra bighorn herds. Should Sierra bighorn herds increase in the future and reach recovery targets, an evaluation of what constitutes "acceptable" levels of predation will be warranted; however, predation monitoring and management are likely going to be a part of the management toolbox for Sierra bighorn for the foreseeable future.

\section{ACKNOWLEDGEMENTS}

Funding for animal captures and GPS collars was provided by Federal Assistance in Wildlife Restoration grants, Endangered Species Conservation and Recovery (Section 6) grants, California Department of Fish and Wildlife, California Wild Sheep Foundation, Yosemite Conservancy, Sierra Nevada Bighorn Sheep Foundation, Wild Sheep Foundation, and U.S. Fish and Wildlife Service. Captures were made possible with the assistance from pilots M. Breiling, S. DeJesus, G. Pope, J. Pope, G. Schales, M. Shelton, and R. Swisher. Field assistance was provided by A. P. Few, T. F. Calfee, B. E. Hatfield, V. M. Davis, J. L. Fusaro, D. F. Jensen, K. Anderson, C. P. Massing, S. Forshee, E.Siemion, J. Weissman, E. Otto, J. Leary, P. Prentice, J. Runcie, J. A. Sturgill, J. A. Erlenbach, K. Ellis, H. E. Johnson, L. E. Greene, C. A. Schroeder, B. A. Gonzales, L. Konde, V. C. Bleich, B. M. Pierce, J. T. Villepique, D. B. Spitz, A. C. Sturgill, M. L. C. Kane, M. A. Kiner, K. M. Ellis, M. Dodd, L. R. Gable, A. H. Peet, G. M. Foote, K. E. Nelson, J. A. Erlenbach, R. J. Spaulding, A. E. Feinberg, A. C. Lawrence, T. M. Glenner, B. A. Teagle, W. O. Livingston, D. E. Rivers, G. L. Cadwallader, W. L. Loeper, and C. C. Noear.

\section{LITERATURE CITED}

Beausoleil, R. A., G. M. Koehler, B. T. Maletzke, B. N. Kertson, and R. B. Wielgus. 2013. Research to regulation: cougar social behavior as a guide for management. Wild- 
life Society Bulletin 37:680-688.

Beausoleil, R. A., L. S. Welfelt, I. N. Keren, B. N. Kertson, B. T. Maletzke, and G. M. Koehler. 2021. Long-term evaluation of cougar density and application of risk analysis for harvest management. Journal of Wildlife Management 85:462-473.

Bender, L. C., and O. C. Rosas-Rosas. 2016. Compensatory puma predation on adult female mule deer in New Mexico. Journal of Mammalogy 97:1399-1405.

Benson, J. F., P. J. Mahoney, T. W. Vickers, J. A. Sikich, P. Beier, S. P. D. Riley, H. B. Ernest, and W. M. Boyce. 2019. Extinction vortex dynamics of top predators isolated by urbanization. Ecological Applications 29:e01868.

Boertje, R. D., P. Valkenburg, and M. E. McNay. 1996. Increases in moose, caribou, and wolves following wolf control in Alaska. Journal of Wildlife Management 60:474-489.

Bowden, D. C., and R. C. Kufeld. 1995. Generalized mark-sight population size estimate applied to Colorado moose. Journal of Wildlife Management 59:840-851.

Bowyer, R. T., V. C. Bleich, K. M. Stewart, J. C. Whiting, and K. L. Monteith. 2014. Density dependence in ungulates: a review of causes, and concepts with some clarifications. California Fish and Game 100:550-572.

Brody, J., H. Johnson, M. Mitchell, P. Zager, K. Proffit, M. Hebblewhite, M. Kauffman, B. Johnson, J. Bissonette, C. Bishop, J. Gude, J. Herbert, K. Hersey, M. Hurley, P. M. Lukacs, S. McCorquodale, E. McIntire, J. Nowak, H. Sawyer, D. Smith, and P. J. White. 2013. Relative influence of human harvest, carnivores, and weather on adult female elk survival across western North America. Journal of Applied Ecology 50:295-305.

Buchalski, M. R., B. N. Sacks, D. A. Gille, M. C. T. Penedo, H. B. Ernest, S. A. Morrison, and W. M. Boyce. 2016. Phylogeographic and population genetic structure of bighorn sheep (Ovis canadensis) in North American deserts. Journal of Mammalogy 97:823-838.

Cain, III, J. W., R. C. Karsch, E. J. Goldstein, E. M. Rominger, and W. R. Gould. 2019. Survival and cause-specific mortality of desert bighorn sheep lambs. Journal of Wildlife Management 83:251-259.

Center for Biological Diversity and the Mountain Lion Foundation. 2019. A petition to list the Southern California/Central Coast Evolutionarily Significant Unit (ESU) of mountain lions as threatened under the California Endangered Species Act (CESA). Available from: https://nrm.dfg.ca.gov/FileHandler. ashx?DocumentID=171208\&inline (Accessed 9 Mar 2021)

Chow, L. S. 1992. Population dynamics and movement patterns of bighorn sheep reintroduced in the Sierra Nevada, California. Cooperative National Park Resources Studies Unit, University of California, Davis, CA, USA

Conner, M. M., T. R. Stephenson, D. W. German, K. L. Monteith, A. P. Few, and E. H. Bair. 2018. Survival analysis: informing recovery of Sierra Nevada bighorn sheep. Journal of Wildlife Management 82:1442-1458.

Cougar Management Guidelines Working Group. 2005. Cougar management guidelines. Wild Futures, Bainbridge Island, WA, USA.

Craven, S., T. Barnes, and G. Kania. 1998. Toward a professional position on the translocation of problem wildlife. Wildlife Society Bulletin 26:171-177.

Davis, J. L., S. W. Carlson, C. C. Coolahan, and D. L. Orthmeyer. 2012. Sierra Nevada bighorn sheep recovery program: the role of USDA Wildlife Services, 1999-2011. 
USDA Wildlife Services, Sacramento, CA, USA.

DeCesare, N. J., M. Hebblewhite, P. M. Lukacs, and D. Hervieux. 2016. Evaluating sources of censoring and truncation in telemetry-based survival data. Journal of Wildlife Management 80:138-148.

Dellinger, J. A., and S. G. Torres. 2020. A retrospective look at mountain lion populations in California (1906-2018). California Fish and Wildlife 106:66-85.

Dellinger, J. A., K. D. Gustafson, D. J. Gammons, H. B. Ernest, and S. G. Torres. 2020. Minimum habitat thresholds required for conserving mountain lion genetic diversity. Ecology and Evolution 10:10687-10697.

Douglas, C. L, and D. M. Leslie, Jr. 1999. Management of bighorn sheep. Pages 238-262 in R. Valdez and P. R. Krausman, editors. Mountain Sheep of North America. The University of Arizona Press, Tucson, AZ, USA.

Elbroch, L, M., and H. U. Wittmer. 2013. The effects of puma prey selection and specialization on less abundant prey in Patagonia. Journal of Mammalogy 94:259-268.

Festa-Bianchet, M., T. Coulson, J. Gaillard, J. T. Hogg, and F. Pelletier. 2006. Stochastic predation events and population persistence in bighorn sheep. Proceedings of the Royal Society B 273:1537-1543.

Few, A. P., K. Knox, D.W. German, J. D. Wehausen, and T. R. Stephenson. 2015. 2015 translocation plan for Sierra Nevada bighorn sheep: a focus on strategic planning. California Department of Fish and Wildlife, Bishop, CA, USA.

Frankham, R. 1995. Effective population size/adult population size ratios in wildlife: a review. Genetical Research 66:95-107.

Forrester, T. D., and H. U. Wittmer. 2013. A review of the population dynamics of mule deer and black-tailed deer Odocoileus hemionus in North America. Mammal Review 43:292-308.

Geist, V. 1971. Mountain sheep, a study in behavior and evolution. University of Chicago Press, Chicago, IL, USA.

German, D. W., and T. R. Stephenson. 2018. Cost-benefit analysis of mountain lion management for the recovery of Sierra Nevada bighorn sheep. Proceedings of the Vertebrate Pest Conference 28:132-144.

Goldstein, E. J., and E. M. Rominger. 2012. A comparison of mortality rates for desert and Rocky Mountain bighorn sheep under two cougar removal regimes. Biennial Symposium of the Northern Wild Sheep and Goat Council 18:137-145.

Griffin, K. A., M. Hebblewhite, H. S. Robinson, P. Zager, S. M. Barber-Meyer, D. Christianson, S. Creel, N. C. Harris, M. A. Hurley, D. H. Jackson, B. K. Johnson, W. L. Myers, J. D. Raithel, M. Schlegel, B. L. Smith, C. White, and P. J. White. 2011. Neonatal mortality of elk driven by climate, predator phenology and predator community composition. Journal of Animal Ecology 80:1246-1257.

Gustafson, K. D., R. B. Gagne, T. W. Vickers, S. P. Riley, C. C. Wilmers, V. C. Bleich, B. M. Pierce, M. Kenyon, T. L. Drazenovich, J. A. Sikich, W. M. Boyce, and H. B. Ernest. 2019. Genetic source-sink dynamics among naturally structured and anthropogenically fragmented puma populations. Conservation Genetics 20:215227.

Gustafson, K. D., T. W. Vickers, W. M. Boyce, and H. B. Ernest. 2017. A single migrant enhances the genetic diversity of an inbred puma population. Royal Society Open Science 4:170115.

Harris, G., L. Smythe, and R. Henry. 2009. Predation by mountain lions is capable of caus- 
ing desert bighorn sheep population to decline at Kofa National Wildlife Refuge, Arizona. Desert Bighorn Council Transactions 50:40-53.

Heisey, D. M., and B. R. Patterson. 2006. A review of methods to estimate cause-specific mortality in the presence of competing risks. Journal of Wildlife Management 70:1544-1555.

Hurley, M. A., J. W. Unsworth, P. Zager, M. Hebblewhite, E. O. Garton, D. M. Montgomery, J. R. Skalski, and C. I. Maycock. 2011. Demographic response of mule deer to experimental reduction of coyotes and mountain lions in southeastern Idaho. Wildlife Monographs 178:1-33.

Johnson, H. E., H. Hebblewhite, T. R. Stephenson, D. W. German, B. M. Pierce, and V. M. Bleich. 2013. Evaluating apparent competition in limiting the recovery of an endangered ungulate. Oecologia 171:295-307.

Johnson, H. E., L. S. Mills, T. R. Stephenson, and J. D. Wehausen. 2010. Populationspecific vital rate contributions influence management of an endangered ungulate. Ecological Applications 20:1753-1765.

Knopff, K. H., A. A. Knopff, A. Kortello, and M. S. Boyce. 2010. Cougar kill rate and prey composition in a multiprey system. Journal of Wildlife Management 74:14351447.

Laundré, J. W., L. Hernandez, and S. G. Clark. 2006. Impact of puma predation on the decline and recovery of a mule deer population in southeastern Idaho. Canadian Journal of Zoology 84:1555-1565.

Leach, H. R., J. M. Brode, and S. J. Nicola. 1974. At the crossroads 1974. A report on California's endangered and rare fish and wildlife. California Department of Fish and Game, Sacramento, CA, USA.

Lewis, K. P., S. E. Gullage, D. A. Fifield, D. H. Jennings, and S. P. Mahoney. 2017. Manipulations of black bear and coyote affect caribou calf survival. Journal of Wildlife Management 81:122-132.

Logan, K. A., and L. L. Sweanor. 2001. Desert Puma: Evolutionary Ecology and Conservation of an Enduring Carnivore. Island Press, Washington, D.C., USA.

Los Angeles Times Editorial Board. 2020. Editorial: California's mountain lions are already under threat. Stop killing more of them. Los Angeles Times. Available from: https://www.latimes.com/opinion/story/2020-02-21/la-ed-mountain-liondepredation (Accessed 15 Dec 2020)

Lovett, G. M., D. A. Burns, C. T. Driscoll, J. C. Jenkins, M. J. Mitchell, L. Rustad, J. G. Shanley, G. E. Likens, and R. Haeuber. 2007. Who needs environmental monitoring? Frontiers in Ecology and the Environment 5:253-260.

McBride, R. T., R. T. McBride, R. M. McBride, and C. E. McBride. 2008. Counting pumas by categorizing physical evidence. Southeastern Naturalist 7:381-400.

Mosnier, A., D. Boisjoly, R. Courtois, and J. Oullet. 2008. Extensive predator space use can limit the efficacy of a control program. Journal of Wildlife Management 72:483491.

Muth, R. M., and W. V. Jamison. 2000. On the destiny of deer camps and duck blinds: the rise of the animal rights movement and the future of wildlife conservation. Wildlife Society Bulletin 28:841-851.

Murray, D. L., D. W. Smith, E. E. Bangs, C. Mack, J. K. Oakleag, J. Fontaine, D. Boyd, M. Jiminez, C. Niemeyer, T. J. Meier, D. Stahler, J. Holyan, and V. J. Asher. 2010. Death from anthropogenic causes is partially compensatory in recovering wolf 
populations. Biological Conservation 143:2514-2524.

Parsons, Z. D. 2007. Cause specific mortality of desert bighorn sheep lambs in the Fra Cristobal Mountains, New Mexico, USA. Thesis, University of Montana, Missoula, MT, USA.

Perry, D., and G. Perry. 2007. Improving interactions between animal rights groups and conservation biologists. Conservation Biology 22:27-35.

Pierce, B. M., V. C. Bleich, and R. T. Bowyer. 2000. Social organization of mountain lions: does a land-tenure system regulate population size? Ecology 81:1533-1543.

Pierce, B. M., V. C., Bleich, J. D. Wehausen, and R. T. Bowyer. 1999. Migratory patterns of mountain lions: implications for social regulation and conservation. Journal of Mammalogy 80:986-992.

Pike, N., T. Tully, P. Haccou, and R. Ferriere. 2004. The effect of autocorrelation in environmental variability on the persistence of populations: an experimental test. Proceedings of the Royal Society London B 271:2143-2148.

Pollock, K. H., S. R. Winterstein, C. M. Bunck, and P. D. Curtis. 1989. Survival analysis in telemetry studies: the staggered entry design. Journal of Wildlife Management 53:7-15.

Robinson, H. S., R. B. Wielgus, H. S. Cooley, and S. W. Cooley. 2008. Sink populations in carnivore management: cougar demography and immigration in a hunted population. Ecological Applications 18:1028-1037.

Rominger, E. M. 2018. The Gordian knot of mountain lion predation and bighorn sheep. Journal of Wildlife Management 82:19-31.

Rominger, E. M., and E. M. Weisenberger 2000. Biological extinction and a test of the "conspicuous individual hypothesis" in the San Andreas mountains, New Mexico. North American Wild Sheep Conference 2:293-307.

Rominger, E. M., H. A. Whitlaw, D. L. Weybright, W. C. Dunn, and W. B. Ballard. 2004. The influence of lion predation on bighorn sheep translocations. Journal of Wildlife Management 68:993-999.

Ross, P. I., M. G. Jalkotzy, and M. Festa-Bianchet. 1997. Cougar predation on bighorn sheep in southwestern Alberta during winter. Canadian Journal of Zoology 75:771-775.

Ruth, T.K., K.A. Logan, L.L. Sweanor, M.G. Hornocker, and L.J. Temple. 1998. Evaluating cougar translocation in New Mexico. Journal of Wildlife Management 62: 1264-1275.

Sandercock, B. K., E. B. Nilsen, H. Brøseth, and H. C. Pedersen. 2011. Is hunting mortality additive or compensatory to natural mortality? Effects of experimental harvest on the survival and cause-specific mortality of willow ptarmigan. Journal of Animal Ecology 80:244-258.

Sierra Nevada Bighorn Sheep Interagency Advisory Group. 1984. Sierra Nevada bighorn sheep recovery and conservation plan. Bishop, CA, USA.

Serrouya, R., M. J. Wittmann, B. N. McLellan, H. U. Wittmer, and S. Boutin. 2015. Using predator-prey theory to predict outcomes of broad scale experiments to reduce apparent competition. The American Naturalist 185:665-679.

Stephenson, T. R., D. W. German, E. F. Cassirer, D. P. Walsh, M. E. Blum, M. Cox, K. M. Stewart, and K. L. Monteith. 2020. Linking population performance to nutritional condition in an alpine ungulate. Journal of Mammalogy 101:1244-1256.

Stephenson, T. R., J. D. Wehausen, A. P. Few, D. W. German, D. F. Jensen, D. Spitz, K. Knox, B. M. Pierce, J. L. Davis, J. Ostergard, and J. Fusaro. 2012. 2010-2011 an- 
nual report of the Sierra Nevada Bighorn Sheep Recovery Program: a decade in review. California Department of Fish and Game, Bishop, CA, USA.

U.S. Fish and Wildlife Service (USFWS). 1999. Endangered and threatened wildlife and plants; emergency rule to list the Sierra Nevada distinct population segment of California bighorn sheep as endangered. Federal Register 64:19300-19309.

U.S. Fish and Wildlife Service (USFWS). 2007. Recovery Plan for the Sierra Nevada Bighorn Sheep. Pacific Southwest Region, Sacramento, CA, USA.

van de Kerk, M., D. P. Onorato, J. A. Hostetler, B. M. Bolker, and M. K. Oli. 2019. Dynamics, persistence, and genetic management of the endangered Florida panther population. Wildlife Monographs 203:3-35.

Vera, A. 2020. First California mountain lion killed under state's new depredation law. CNN website. Available from: https:/www.cnn.com/2020/02/11/us/californiadepredation-law-mountain-lion-killed/index.html (Accessed 15 Dec 2020)

Wehausen, J. D. 1996. Effects of lion predation on bighorn sheep in the Sierra Nevada and Granite Mountains of California. Wildlife Society Bulletin 24:471-479.

Wehausen, J. D. 1980. Sierra Nevada bighorn sheep: history and population ecology. Dissertation, University of Michigan, Ann Arbor, MI, USA.

Wehausen, J. D., and F. L. Jones. 2014. The historical distribution of bighorn sheep in the Sierra Nevada, California. California Fish and Game 100:417-435.

Wehausen, J. D., and R. R. Ramey, II. 2000. Cranial morphometric and evolutionary relationships in the northern range of Ovis canadensis. Journal of Mammalogy 81:145-161.

Wehausen, J. D., S. T. Kelley, and R. R. Ramey, II. 2011 Domestic sheep, bighorn sheep, and respiratory disease: a review of the experimental evidence. California Fish and Game 97:7-24.

Wehausen, J. D., V. C. Bleich, and R. A. Weaver. 1987. Mountain sheep in California: a historical perspective on 108 years of full protection. Transactions of the Western Section of the Wildlife Society 23:65-74.

Wehausen, J. D., V. C. Bleich, and R. R. Ramey, II. 2005. Correct nomenclature for Sierra Nevada bighorn sheep. California Fish and Game 91:216-218.

Wittmer, H. U., M. Hasenbank, L. M. Elbroch, and A. J. Marshall. 2014. Incorporating preferential prey selection and stochastic predation into population viability analysis for rare prey species. Biological Conservation 172:8-14.

Wolfe, M. L., D. N. Koons, D. C. Stoner, P. Terletzky, E. M. Gese, D. M. Choate, and L. M. Aubry. 2015. Is anthropogenic cougar mortality compensated by changes in natural mortality in Utah? Insight from long-term studies. Biological Conservation 182:187-196.

Submitted 22 December 2020

Accepted 2 February 2021

Associate Editor was D. Applebee 